\title{
Snapping Pes Syndrome after Unicompartmental Knee Arthroplasty
}

Hiroshi Inui, MD, Shuji Taketomi, MD, Ryota Yamagami, MD, Keitaro Tahara, MD, and Sakae Tanaka, MD

Department of Orthopaedic Surgery, Faculty of Medicine, The University of Tokyo, Tokyo, Japan

Snapping pes syndrome is defined as a snapping sensation in the medial knee caused by pes anserinus and rarely occurs. Snapping pes syndrome after unicompartmental knee arthroplasty (UKA) has not been reported yet. We experienced two cases with this syndrome after UKA. Conservative treatment was effective in one case, while surgical excision of the gracilis tendon was necessary to relieve painful snapping in the other case. The main cause of the first case might be posteromedial overhang of the tibial tray that reached up to $5 \mathrm{~mm}$. The probable cause of the second case was posteromedial overhang of the mobile bearing.

Keywords: Knee, Arthroplasty, Unicompartmental, Snapping, Gracillis

Snapping symptoms around the knee are rare and are usually reported to occur around the lateral aspect of the knee caused by the biceps tendon, popliteus tendon, and iliotibial band ${ }^{1)}$. Snapping symptoms in the medial aspect of the knee are extremely rare $^{2-4)}$. Bollen and Arvinte ${ }^{3)}$ reported four cases with snapping of the semitendinosus and gracilis tendons, and they termed this condition as "snapping pes syndrome". Here, we first report two cases of snapping pes syndrome that occurred after unicompartmental knee arthroplasty (UKA).

\section{Case Reports}

\section{Case 1}

A 64-year-old male who suffered from osteoarthritis of the right knee underwent a UKA (Biomet, Swindon, UK) on the

Received September 21, 2015; Revised (1st) October 26, 2015;

(2nd) November 18, 2015; Accepted November 25, 2015

Correspondence to: Hiroshi Inui, MD

Department of Orthopaedic Surgery, Faculty of Medicine, The University of Tokyo, 7-3-1 Hongo, Bunkyo-ku, Tokyo 113-0033, Japan Tel: +81-3-3815-5411, Fax: +81-3-3818-4082

E-mail: hiroshi_inu0707@yahoo.co.jp

This is an Open Access article distributed under the terms of the Creative Commons Attribution Non-Commercial License (http://creativecommons.org/licenses/by-nc/4.0/) which permits unrestricted non-commercial use, distribution, and reproduction in any medium, provided the original work is properly cited. right knee. Preexisting pain in the medial joint disappeared soon after the operation. However, 4 months postoperatively, he began to feel a painful snapping sensation on the posteromedial side, particularly when he rose from a chair after prolonged sitting.

On examination, moderate swelling and tenderness in the posteromedial corner were observed and there was a palpable clicking over the posteromedial corner of the knee when the knee was moved from flexion to extension at approximately $60^{\circ}$ of flexion. The passive range of motion (ROM) was $0^{\circ}$ to $135^{\circ}$, and there was no varus-valgus or rotational instability.

UKA implants were well aligned on the radiographs of the right knee (Fig. 1). The hip-knee-ankle (HKA) angle changed from $11^{\circ}$ varus to $5^{\circ}$ varus on the postoperative radiographs. However, the tibial component was implanted too medially, and the amount of medial overhang was $4 \mathrm{~mm}$ on the plain radiograph and posteromedial overhang reached up to $5 \mathrm{~mm}$ on the computed tomography (CT) images (Figs. 1 and 2).

Conservative treatment of nonsteroidal anti-inflammatory drugs and hamstring stretching was done. Two years after the operation, the pain caused by the snapping almost disappeared, although he felt a slight snapping sensation.

\section{Case 2}

A 71-year-old female with osteonecrosis of the right knee underwent a navigation-assisted UKA on the right knee. Preexisting severe pain in the medial joint was relieved after the operation. 
However, she began to feel another kind of pain on the medial side 1 month after the operation. Seven months after the operation, she began to feel a snapping sensation over the posteromedial aspect of the right knee. Eight months postoperatively, the pain caused by this snapping got worse, and nonsteroidal antiinflammatory drugs and physiotherapy courses were ineffective. Eventually, additional surgery was scheduled.

Upon clinical examination, moderate swelling and tenderness along the gracilis tendon were observed, and there was a palpable and painful clicking over the posteromedial corner of the knee when actively extending the knee from flexion at approximately $30^{\circ}$ of flexion. The passive ROM was $0^{\circ}$ to $130^{\circ}$, and there was no varus-valgus or rotational instability.

UKA implants were well aligned on the radiographs of her right
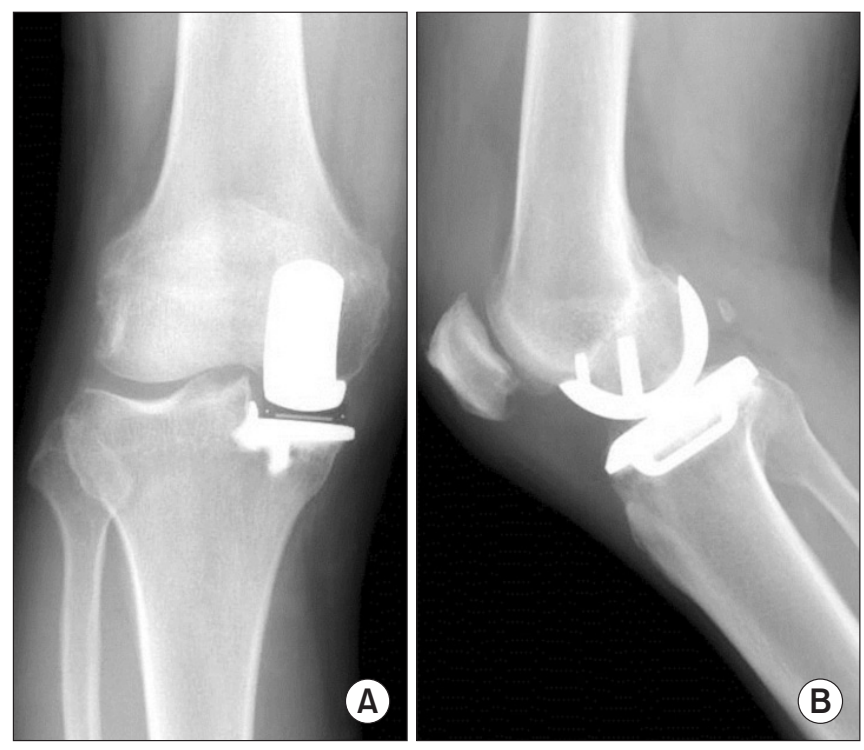

Fig. 1. Postoperative radiographs of case 1. (A) Anteroposterior view showing a 4-mm overhang of the tibial component. (B) Lateral view. knee (Fig. 3). The HKA angle changed from $10^{\circ}$ varus to $4^{\circ}$ varus on the postoperative radiographs. Neither plain radiographs nor CT images examined in extension position showed an excessive implant overhang. However, reconstructed CT images revealed an excessive overhang of the mobile bearing up to $4 \mathrm{~mm}$ at the posteromedial corner (Fig. 4).

A diagnostic arthroscopy of her left knee was performed first and no intraarticular pathologies that would cause the snapping were found. Through an 8-cm medial curved skin incision, the medial patellar retinaculum was incised at the anterior border of the sartorius, and the semitendinosus and gracilis tendons were exposed. Passive extension of the knee reproduced the snapping, which turned out to be a phenomenon of subluxation of the gracilis tendon around the semimembranosus (Fig. 5). Approxi-
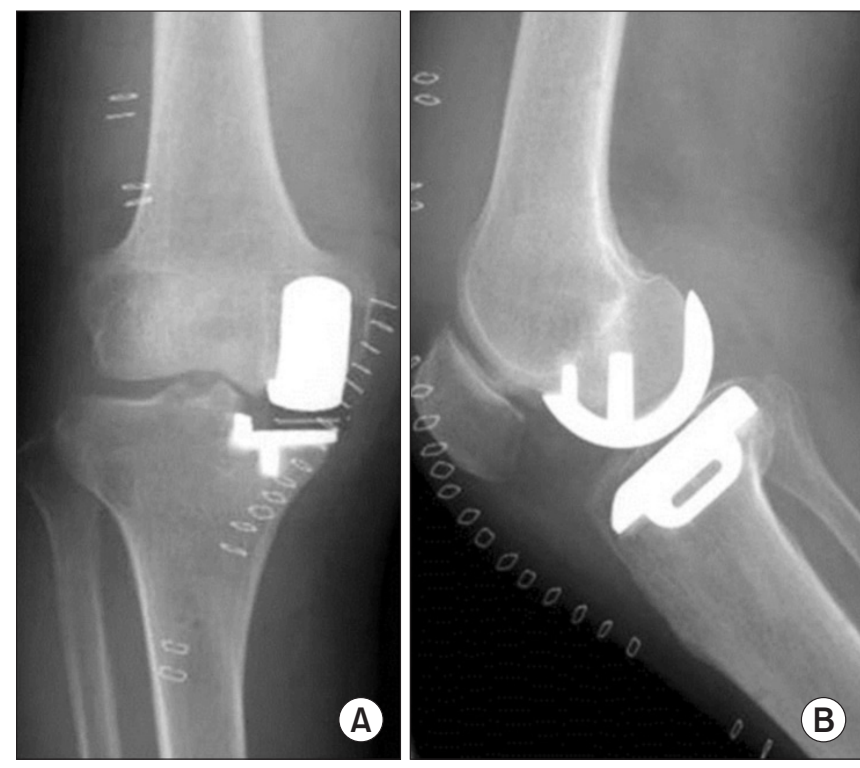

Fig. 3. Postoperative radiographs of case 2 showing ideal implantation. (A) Anteroposterior view. (B) Lateral view.
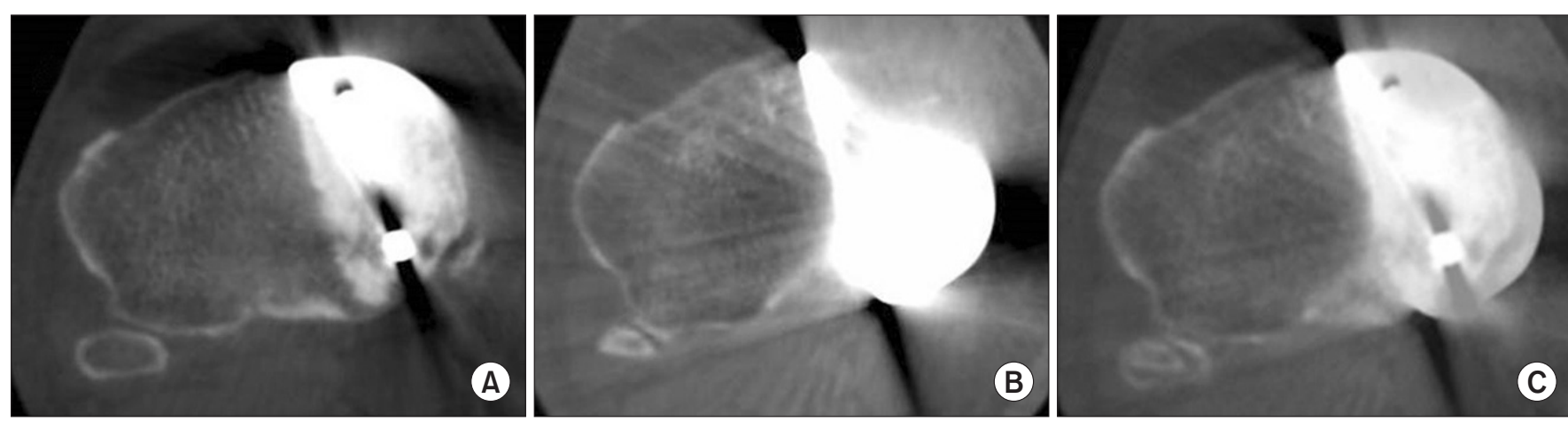

Fig. 2. Postoperative computed tomography images. (A) Image at the horizontal bone cutting level. (B) Image at the tibial component surface. (C) Combined image showing a 5 -mm overhang at the posteromedial corner. 
mately $6 \mathrm{~cm}$ of the gracilis tendon around the semimembranosus was resected and the snapping disappeared. The patient was allowed to walk without any limitation soon after the operation and found that the painful snapping at the posteromedial corner had disappeared. Snapping symptom has not recurred for 18 months after the additional operation.

Both patients were informed that their data would be submitted for publication, and they gave their consent for the report to be published.

\section{Discussion}

Postoperative complications of UKA have often been reported ${ }^{5)}$.

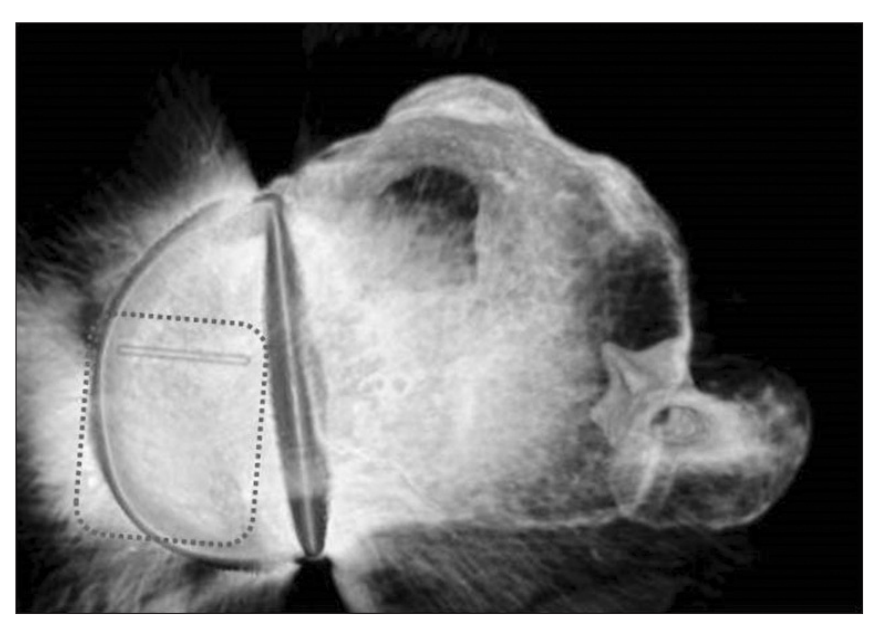

Fig. 4. Postoperative reconstructed computed tomography image of case 2 showing a posteromedial overhang of the mobile bearing with the dotted square indicating periphery of the mobile bearing.

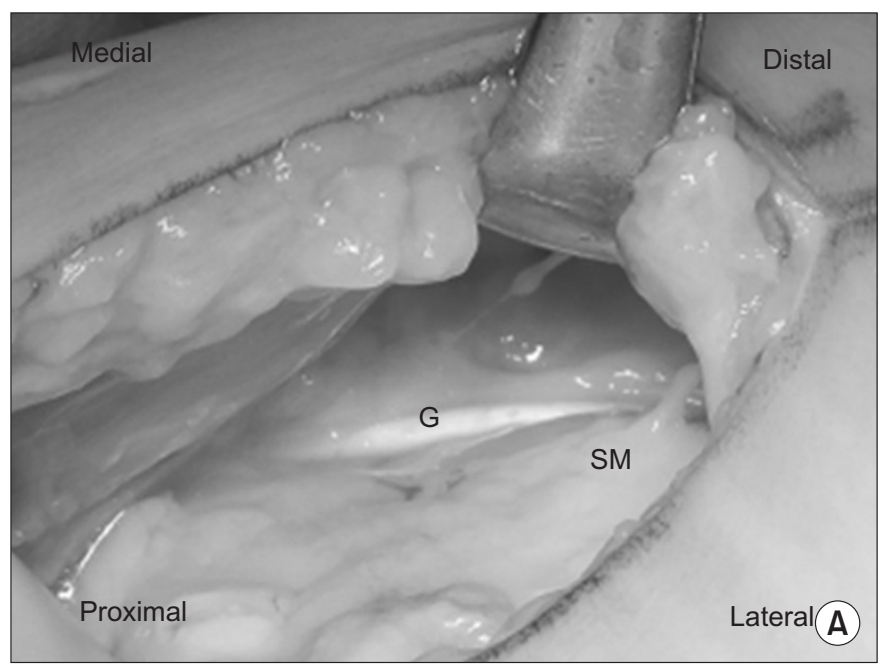

However, none have reported the complication of snapping pes syndrome after UKA. Snapping symptoms around the medial aspect of the knee have rarely been reported, and in most cases, patients are young or middle-aged. Regarding elderly patients, Tensho et al. ${ }^{6}$ presented a case of snapping pes syndrome after total knee arthroplasty and that was the only report after a knee arthroplasty. In their case, a bony prominence of residual osteophyte at the posteromedial corner of the tibia and a change in the alignment were presumed to be the two main possible causes of the snapping symptoms.

The most probable cause of snapping in case 1 was an excessive overhang of the tibial tray, which reached up to $5 \mathrm{~mm}$ at the posteromedial corner. Gudena et al. ${ }^{7)}$ reported that a $2 \mathrm{~mm}$ or less overhang of the tibial component is ideal to minimize the pain from excessive medial collateral ligament loading in UKA. Excessive medial and posteromedial overhang of the tibial tray should be avoided. The probable cause in case 2 was an excessive posteromedial overhang of the mobile bearing (Fig. 4).

A variety of causes of residual pain after UKA, such as aseptic loosening, progression of arthritis on the lateral side, infection, and medial overhang, have been reported ${ }^{5,7-9)}$. However, there are still some UKA cases where pain is called "unexplained pain" because of the lack of definite causes. Recent papers have reported that proximal tibial strains following UKA and preoperative bone marrow edema could be possible causes of unexplained pain ${ }^{10)}$. Snapping pes syndrome could also be one of the causes of unexplained pain after UKA.

We have experienced a 11 out of 111 UKA cases (10\%) incidence of tibial component excessive overhang $(\geq 3 \mathrm{~mm})^{9)}$, and three of them felt some pain around the medial side of the knee one year

Fig. 5. Intraoperative findings with the knee flexed to $60^{\circ}(\mathrm{A})$ and $30^{\circ}(\mathrm{B})$ : gracilis tendon $(\mathrm{G})$ subluxed around the semimembranosus $(\mathrm{SM})$ at $30^{\circ}$. 
after operation. However, there were not any other cases that felt snapping sensation even with medial overhang of the tibial component. The reason was difficult to clarify, but we presumed that this might be because snapping syndrome occurred at the posteromedial corner, not on the medial side. Evaluation of the amount of overhang at the posteromedial corner with $\mathrm{CT}$ images will be necessary to elucidate it.

With regard to surgical treatment of snapping syndrome, tendon release at the attachment site has often been reported. However, there were some failure cases of this harvesting at the attachment site technique. Bollen and Arvinte ${ }^{3)}$ reported, after the examination of real-time ultrasound, they determined to harvest the semitendinosus tendon. However, the patient's painful snapping sensation persisted after the operation. Additional operation of harvesting the gracilis tendon resolved the snapping symptom. To prevent conduction of further operation, we wanted to confirm the snapping tendon directly so that we did not utilize the harvesting at the attachment site method.

There was a limitation of the current study. We diagnosed these cases mainly based on clinical examination and did not use dynamic ultrasound in these cases. Though snapping symptoms were easily palpable and diagnosis was confirmed by three expert knee surgeons (HI, ST, and RY), we should have examined with real-time ultrasound to reveal the pathology more clearly $\mathrm{y}^{3)}$.

Knee surgeons should be aware of the presence of pes snapping syndrome after UKA as a postoperative complication. Meticulous implantation, intraoperative evaluation of the movement of the mobile bearing if mobile bearing UKA is performed, and adequate preoperative assessments, including magnetic resonance imaging, would prevent snapping pes syndrome after UKA.

\section{Conflict of Interest}

No potential conflict of interest relevant to this article was reported.

\section{References}

1. Bach BR Jr, Minihane K. Subluxating biceps femoris tendon: an unusual case of lateral knee pain in a soccer athlete: a case report. Am J Sports Med. 2001;29:93-5.

2. Lyu SR, Wu JJ. Snapping syndrome caused by the semitendinosus tendon: a case report. J Bone Joint Surg Am. 1989;71: 303-5.

3. Bollen SR, Arvinte D. Snapping pes syndrome: a report of four cases. J Bone Joint Surg Br. 2008;90:334-5.

4. Geeslin AG, LaPrade RF. Surgical treatment of snapping medial hamstring tendons. Knee Surg Sports Traumatol Arthrosc. 2010;18:1294-6.

5. Ko YB, Gujarathi MR, Oh KJ. Outcome of unicompartmental knee arthroplasty: a systematic review of comparative studies between fixed and mobile bearings focusing on complications. Knee Surg Relat Res. 2015;27:141-8.

6. Tensho K, Aoki T, Morioka S, Narita N, Kato H, Saito N. Snapping pes syndrome after total knee arthroplasty. Knee Surg Sports Traumatol Arthrosc. 2014;22:192-4.

7. Gudena R, Pilambaraei MA, Werle J, Shrive NG, Frank CB. A safe overhang limit for unicompartmental knee arthroplasties based on medial collateral ligament strains: an in vitro study. J Arthroplasty. 2013;28:227-33.

8. Price AJ, Waite JC, Svard U. Long-term clinical results of the medial Oxford unicompartmental knee arthroplasty. Clin Orthop Relat Res. 2005;(435):171-80.

9. Chau R, Gulati A, Pandit H, Beard DJ, Price AJ, Dodd CA, Gill HS, Murray DW. Tibial component overhang following unicompartmental knee replacement: does it matter? Knee. 2009;16:310-3.

10. Jacobs CA, Christensen CP, Karthikeyan T. Subchondral bone marrow edema had greater effect on postoperative pain after medial unicompartmental knee arthroplasty than total knee arthroplasty. J Arthroplasty. 2016;31:491-4. 